\title{
A Rare Case of Gastric Outlet Obstruction due to Large Intramural Duodenal Hematoma Following Endotherapy for Bleeding Duodenal Ulcer in a Patient with End-stage Renal Disease
}

\author{
Vineet Kumar Gupta, Ram Chandra Soni
}

Department of

Gastroenterology, Asian

Institute of Medical Sciences,

Faridabad, Haryana, India
We report a very rare case and probably the first from India of gastric outlet obstruction due to a large intramural duodenal hematoma following combination endotherapy with hemoclipping and injection adrenaline 1:10,000 for actively bleeding duodenal ulcer in an elderly male patient with diabetes, hypertension, and end-stage renal disease on maintenance hemodialysis. The patient improved to approximately 6 weeks of conservative treatment with nasojejunal feeding.

KEYWORDS: End-stage renal disease, gastric outlet obstruction, hemodialysis, intramural duodenal hematoma

\section{INTRODUCTION}

$\mathcal{I}$ $\mathcal{I}$ ntramural duodenal hematoma is a rare condition, is also and less commonly reported as a complication of anticoagulant therapy, blood dyscrasias, pancreatic disease, and collagen vascular disease. ${ }^{[1-6]}$ Intramural hematoma of the duodenum has been reported as a complication of diagnostic or therapeutic endoscopy. ${ }^{[7-15]}$ We report a rare case of gastric outlet obstruction caused by intramural duodenal hematoma after hemoclipping and injection adrenaline 1:10,000 of bleeding duodenal ulcer in a patient with end-stage renal disease on maintenance hemodialysis. In literature, there are hardly any case reports of gastric outlet obstruction with the same etiology and this is the first from India although cases of small bowel obstruction have been reported.

\section{CAse Report}

A 77-year-old diabetic and hypertensive male patient with end-stage renal disease on maintenance hemodialysis (thrice/week) was admitted with 1 week history of melena and generalized weakness. He was not on any antiplatelet or anticoagulation therapy. There was no history of abdominal pain or similar episode in the past. On investigation, he was found to be severely anemic with hemoglobin $(\mathrm{Hb})$ of $5.6 \mathrm{gm} / \mathrm{dl}$. His serum creatinine was $5.5 \mathrm{mg} / \mathrm{dl}$ and serum potassium - $7.5 \mathrm{mEq} / \mathrm{L}$. He had a normal coagulation

\begin{tabular}{|l|l|}
\hline \multicolumn{2}{|c|}{ Access this article online } \\
\hline Quick Response Code: & Website: www.jdeonline.in \\
\hline
\end{tabular}

profile. After initial management in intensive care unit with multiple blood transfusions and anti-hyperkalemic measures, he was taken up for endoscopy. Endoscopy revealed a duodenal bulb ulcer approximately $1 \mathrm{~cm}$ in diameter with visible vessel and active ooze (Forrest type IB). D2 and D3 were normal. Combination therapy of hemoclipping of the visible vessel followed by injection adrenaline 1:10,000 up to approximately $20 \mathrm{ml}$ was done in all four quadrants around the ulcer, and hemostasis was achieved. About 6-8 h later, patient developed acute-onset, continuous, moderate to severe intensity nonradiating epigastric pain which was managed with intermittent intravenous analgesics. At this time, his amylase and lipase levels were within normal limits and electrocardiogram ruled out any acute cardiac event. Over the next 12-24 h, pain intensity reduced but did not subside completely, and he developed abdominal distension and persistent nonbloody retention vomiting. Further, despite receiving 4 units of packed red blood cell transfusion and no obvious blood loss from any site, he continued to have low $\mathrm{Hb}$ (6.5 gm/dl). An urgent computed tomography (CT) whole abdomen with oral and intravenous contrast (after clearance

\section{Address for correspondence: Dr. Vineet Kumar Gupta, Flat No. 7256, Pocket-10, Sector-B, Vasant Kunj, New Delhi - 110 070, India. E-mail: gvineet75@gmail.com}

This is an open access article distributed under the terms of the Creative Commons Attribution-NonCommercial-ShareAlike 3.0 License, which allows others to remix, tweak, and build upon the work non-commercially, as long as the author is credited and the new creations are licensed under the identical terms.

For reprints contact: reprints@medknow.com

How to cite this article: Gupta VK, Soni RC. A rare case of gastric outlet obstruction due to large intramural duodenal hematoma following endotherapy for bleeding duodenal ulcer in a patient with end-stage renal disease. J Dig Endosc 2017;8:199-201. 
from nephrologist) was planned which showed a large hyperdense and nonenhancing mass lesion likely hematoma, in the wall of second part of the duodenum with severe narrowing of the lumen of the duodenum and nonenhancing soft tissue thickening, fat stranding in anterior pararenal space with thickening of the right renal fascia [Figure 1]. Compression at ampulla with mild dilatation of the upstream bile ducts was seen. The stomach was also dilated. A relook endoscopy [Figure 2] was done with minimal air insufflation which revealed a hyperemic, eccentric, and large intramural duodenal hematoma involving the second part of duodenum with luminal compromise. Scope could not negotiate the narrowed lumen. Previous hemoclips were seen in situ with no active bleeding from the ulcer site. In the absence of any gross signs of sepsis, peritonism, obstructive jaundice, or pancreatitis, a combined decision with surgical team to continue with conservative management was taken. A trelumina nasojejunal feeding tube with a gastric suction port was placed across the lesion under fluoroscopic and endoscopic guidance. During this period, he underwent heparin free hemodialysis. He received nasojejunal feedings and was discharged from the hospital with feeding tube in situ after a total stay of 2 weeks. He was followed up in outpatient department and resumed oral feeds at week 3 which was changed to soft and then to normal diabetic renal diet over 6-8 weeks. He is in a stable condition at 4 months of follow-up and undergoing maintenance hemodialysis. In the absence of any published guidelines or any firm indication and in view of significant clinical improvement on regular follow-ups plus financial issues in our setup and last but not the least, radiation risks, any repeat endoscopic or any radiological investigation during this period was not done.

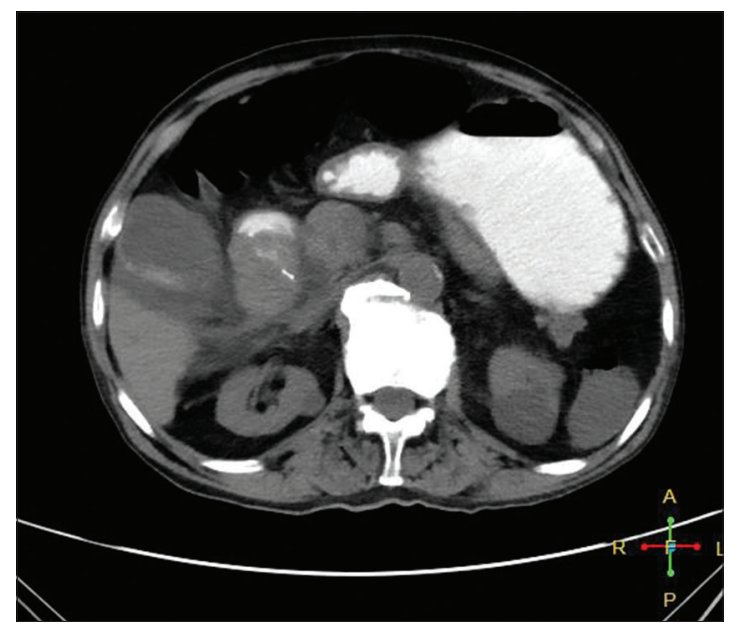

Figure 1: Abdominal computed tomography shows a large hematoma involving the second part of duodenum with gasric outlet obstruction. Size 27 KB. Dimensions $512 \times 512$ pixels

\section{Discussion}

Iatrogenic duodenal intramural hematoma is a rare presentation and this is probably the first case from India that presented as gastric outlet obstruction. In this case, we think that the use of large amount of diluted approximately $20 \mathrm{ml}$ of adrenaline 1:10,000 and needle trauma in high-risk patients such as end-stage renal disease and cirrhosis created a potential space by raising a submucosal flap by hydrodissection, embedding the vessel and allowing it to continue bleeding in the submucosal plane. Once a potential space has been created, pressure of the arterial bleed led to formation of massive dissecting intramural hematoma. Other likely possibilities in this case are anticoagulation during previous hemodialysis and functional coagulopathy in end-stage renal disease patients despite having normal coagulation profile might have increased the risk of bleeding. Relative fixity of the duodenum in retroperitoneum, location ahead of vertebral column and rich vascular plexus make duodenum vulnerable to this unusual complication, especially following blunt trauma to abdomen and may lead to trauma to the submucosal vessels and bleeding in predisposed individuals. Patients with duodenal hematoma usually present with insidious onset of obstruction about $48 \mathrm{~h}$ after the initial injury. The obstructive symptoms are due to a gradual shift of fluid into the hypertonic environment within the intramural hematoma, leading to compression of the duodenum, as in this case. Hematoma usually involves the second and third part of duodenum causing gastric outlet obstruction. Intramural hematoma of the duodenum is treated with either conservative or surgical therapy. When conservative treatment is not effective, other modalities such as surgical drainage (laparotomy, laparoscopic drainage), ultrasound- or CT-guided

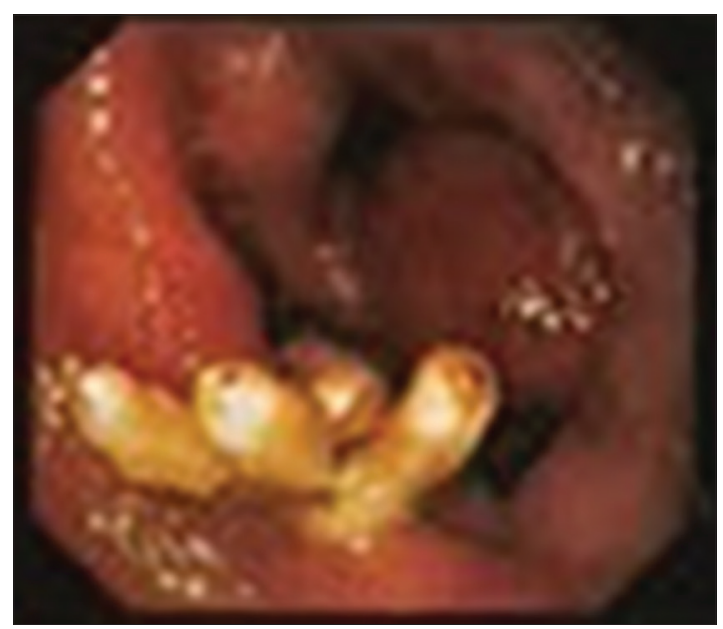

Figure 2: Relook endoscopy shows a large hematoma in the second part of duodenum with complete luminal narrowing. Also seen are the hemoclips in situ 
drainage are used. ${ }^{[16]}$ In addition, endoscopic incision and drainage techniques are also used in the treatment as a more comfortable method. ${ }^{[17]}$ In our case, as there was no emergent indication for any invasive treatment such as sepsis, signs of peritonism, obstructive jaundice, or pancreatitis due to pressure over the ampulla or continued bleeding so a decision to manage the patient conservatively was taken. Gastric outlet obstruction due to the large hematoma resolved quickly because of the rich blood supply of the duodenum.

\section{CONCLUSION}

It should be kept in mind that endoscopic hemostatic procedures, especially large volume adrenaline injection as in this case, in the presence of conditions, predisposing patients to bleeding (e.g., chronic renal failure and hepatic cirrhosis) may lead to complications, and any deterioration should prompt a reassessment, utilizing imaging methods as necessary. Intramural hematoma should be considered in differential diagnosis for patients with no clinical evidence of bleeding (no hematemesis or melena) but with reduced hematocrit levels after endoscopic intervention. In case of complications such as sepsis, nonresolving complete luminal obstruction, acute pancreatitis secondary to pressure on the ampulla, and obstructive jaundice develop and should have a low threshold for other modalities of treatment.

\section{Financial support and sponsorship}

Nil.

\section{Conflicts of interest}

There are no conflicts of interest.

\section{REFERENCES}

1. Jones WR, Hardin WJ, Davis JT, Hardy JD. Intramural hematoma of the duodenum: A review of the literature and case report. Ann Surg 1971;173:534-44.

2. Janson KL, Stockinger F. Duodenal hematoma. Critical analysis of recent treatment technics. Am J Surg 1975;129:304-8.

3. Margolis IB, Carnazzo AJ, Finn MP. Intramural hematoma of the duodenum. Am J Surg 1976;132:779-83.
4. Fingerhut A, Rouffet $\mathrm{F}$, Eugène $\mathrm{C}$, Fendler JP, Hillion $\mathrm{D}$, Ronat R. Nontraumatic intramural hematoma of the duodenum. Report of 4 cases and review of the literature. Digestion 1983;26:231-5.

5. Hayashi $\mathrm{T}$, Nagasue $\mathrm{N}$, Chang $\mathrm{YC}$, Kohno H, Nakamura $\mathrm{T}$. Duodenal stenosis caused by ruptured aneurysms of the pancreaticoduodenal artery - A case report. Jpn J Surg 1989;19:63-6.

6. Weinstock LB, Wu JS, Malden ES, Garcia KM, Rubin BG, Brunt LM. Small bowel obstruction resulting from mesenteric hematoma caused by spontaneous rupture of a jejunal branch artery. Gastrointest Endosc 1999;49(4 Pt 1):537-40.

7. Sisley JF, Bowden TA, Mansberger AR Jr. Pancreatic duct disruption and duodenal hematoma associated with endoscopic retrograde cholangiopancreatography. South Med J 1987;80:1441-3.

8. Ben-Baruch D, Powsner E, Cohen M, Dintsman M. Intramural hematoma of duodenum following endoscopic intestinal biopsy. J Pediatr Surg 1987;22:1009-10.

9. Zinelis SA, Hershenson LM, Ennis MF, Boller M, Ismail-Beigi F. Intramural duodenal hematoma following upper gastrointestinal endoscopic biopsy. Dig Dis Sci 1989;34:289-91.

10. Szajewska H, Albrecht P, Ziolkowski J, Kubica W. Intramural duodenal hematoma: An unusual complication of duodenal biopsy sampling. J Pediatr Gastroenterol Nutr 1993;16:331-3.

11. Karjoo M, Luisiri A, Silberstein M, Kane RE. Duodenal hematoma and acute pancreatitis after upper gastrointestinal endoscopy. Gastrointest Endosc 1994;40:493-5.

12. Lipson SA, Perr HA, Koerper MA, Ostroff JW, Snyder JD, Goldstein RB. Intramural duodenal hematoma after endoscopic biopsy in leukemic patients. Gastrointest Endosc 1996;44:620-3.

13. Sadry F, Hauser H. Fatal pancreatitis secondary to iatrogenic intramural duodenal hematoma: A case report and review of the literature. Gastrointest Radiol 1990;15:296-8.

14. Rohrer B, Schreiner J, Lehnert P, Waldner H, Heldwein W. Gastrointestinal intramural hematoma, a complication of endoscopic injection methods for bleeding peptic ulcers: A case series. Endoscopy 1994;26:617-21.

15. Han SJ, Tsai CC, Mo LR, Tseng LJ, Yau MP. Laparoscopic finding and imaging of the iatrogenic duodenal intramural hematoma. Hepatogastroenterology 1997;44:139-42.

16. Nolan GJ, Bendinelli C, Gani J. Laparoscopic drainage of an intramural duodenal haematoma: A novel technique and review of the literature. World J Emerg Surg 2011;6:42.

17. Pan YM, Wang TT, Wu J, Hu B. Endoscopic drainage for duodenal hematoma following endoscopic retrograde cholangiopancreatography: A case report. World J Gastroenterol 2013;19:2118-21. 